\title{
Response of Very Premature Infants with Bronchopulmonary Dysplasia to Inhaled Salbutamol
}

$\underline{\text { Ha-Nam P. Nguyen }}{ }^{*}$, Dominic Fitzgerald ${ }^{Y}$, M.B.B.S., Ph.D., F.R.A.C.P., and Michael G. Davis ${ }^{Y}$, M.Sc., M.B.Ch.B., F.R.C.P.C., F.R.A.C.P.

To whom correspondence should be addressed:

* Faculty of Medicine McGill University, 3655 Drummond St., Montreal, QC, Canada, H3G 1Y6

${ }^{Y}$ Division of Respiratory Medicine, Montreal Children's Hospital, 2300 Tupper Ave., Montreal, Quebec, Canada, H3H 1P3

\section{ABSTRACT}

Bronchopulmonary Dysplasia (BPD) is the most common chronic respiratory disease found in premature infants following prolonged supplemental oxygen and mechanical ventilation. Although salbutamol, a selective $\boldsymbol{B}_{2}$ agonist, is known to relax the hypertrophied smooth muscles around the small airways in adults, earlier literature has suggested that neonates did not have enough peribronchial smooth muscle for constriction and thus lacked a bronchodilatory response to $\boldsymbol{B}_{2}$ agonists. The present study was designed to determine whether infants of less than 32 weeks gestational age with elevated lung resistance were responsive to salbutamol. Nineteen premature infants (mean gestational age $26.0+/-2.1$ weeks and mean birth weight $851.3+/-244.4$ g) were recruited for the study. Immediately before and 30 minutes after the commencement of nebulized salbutamol administration, a minimum of 15 breaths were measured and analyzed for each patient. From this breath-by-breath analysis, the lung mechanics and Work of Breathing (WOB) were calculated. Results were then compared by paired t-tests. The use of salbutamol resulted in a significant improvement in airway resistance $(p=0.008)$ and tendency for impedance reduction. These results indicate that very premature infants (<32 weeks) with BPD respond favorably to bronchodilators. Although the mechanism of action remains to be elucidated, salbutamol most probably achieves its effects through the relaxation of the hypertrophied peribronchial smooth muscle. Early intervention to relieve airway obstruction may promote early weaning from mechanical ventilation and diminish both duration and severity of BPD.

\section{INTRODUCTION}

Bronchopulmonary dysplasia (BPD) was initially described in 1967 by Northway et al. as a chronic 
respiratory disease of premature infants resulting from prolonged supplemental oxygen and mechanical ventilation (1). This disorder most frequently follows treatment of respiratory distress syndrome (RDS), but may also occur following pneumonia, congenital heart disease and tracheoesophageal fistula (2). Oxygen toxicity from oxidative free radical formation, direct mechanical injury from prolonged, positive-pressure ventilation (barotrauma) and immaturity of developing lung structures are major contributing factors to the progression of BPD $(3,4)$. Clinical manifestations include tachypnea, dyspnea, hypoxemia, and hypercapnea (2), with characteristic chest radiographic features consisting of alternating strands of radiodensity, representing fibrosis and atelectasis, and radiolucent hyperexpanded areas, representing air trapping (5). Although the etiology is multifactorial, the final common pathway of BPD involves both diffuse alveolar damage (DAD) and injury to the conducting airways. As a result, a vicious cycle of increased ventilator requirements and increased lung damage ensues with approximately $40 \%$ of BPD patients dying of their disease during their initial stay in the hospital or shortly after discharge (6).

Over the last 20 years, the increasing survival of premature infants who are born at an earlier gestation and lower birthweight (6) has resulted in longer dependence upon mechanical ventilation and supplemental oxygen. This has led to the emergence of a clear link between increased risk of BPD and decreased gestational age and birthweight (7). Survivors have a marked increase in morbidity due primarily to respiratory disease during their first two years of life (8). These pulmonary changes are chronic and are not reversible in the majority of cases. Indeed, adolescents and young adults with a history of BPD commonly have measurable pulmonary dysfunction including decreased forced expiratory volume in one second $\left(\mathrm{FEV}_{1}\right)$, decreased forced expiratory flow between 25 and 75 percent of vital capacity $\left(\mathrm{FEF}_{25-75}\right)$ and increased airway resistance $\left(R_{L}\right)(9)$. This raises concern about their susceptibility to progressive obstructive pulmonary disease as older adults. Because of the relatively recent recognition of the disease, outcome of BPD in adulthood has not yet been documented. Thus, as the incidence and prevalence of BPD continues to increase, this group of patients will become a substantial component of those suffering from chronic obstructive airway disease in adulthood.

BPD is characterized by an increase in airflow resistance, increased functional residual capacity, and a low dynamic lung compliance. Current treatment aims to reverse the airway obstruction present during the course of the disease. Pharmacotherapy includes corticosteroids for the inhibition of chronic parenchymal inflammatory exudation $(10)$, and diuretics for reduction of airway edema $(11,12)$. Indications for the use of selective $\beta_{2}$-adrenergic agonists, such as salbutamol, in the treatment of very premature babies with BPD remain controversial. Although salbutamol is known to relax the hypertrophied smooth muscles around the small airways in adults, previous literature suggested that neonates do not have enough peribronchial smooth muscle to effectively constrict bronchi, and thus lack a bronchodilatory response to $\beta_{2}$ agonists (13).

Paradoxically, the current authors, as well as other investigators $(14,15,16)$, have demonstrated decreased flow resistance in premature infants of greater than 32 weeks gestational age following salbutamol administration. The present study was designed to determine whether very premature infants of less than 32 weeks gestational age with elevated lung resistance are responsive to salbutamol.

\section{MATERIALS AND METHODS}

\section{Study Population}

Patients from the Neonatal Intensive Care Unit at the Royal Victoria Hospital (Montreal, Quebec, Canada) were enrolled with written and informed consent obtained from parents/guardians. Inclusion criteria were: (i) prematurity (gestational age less than 32 weeks, birth weight less than $1.5 \mathrm{~kg}$ ), (ii) presence of an early clinical course and radiographic evidence consistent with BPD, described as the need for mechanical ventilation for a variable period after birth, ongoing oxygen requirement and an abnormal chest X-ray based upon the definition of Hyde et al. (17), (iii) supplemental $\mathrm{FiO}_{2}$ requirement and (iv) grossly elevated airway 
resistance for maturation. Patients with any documented structural heart disease, major neurological or neuromuscular disorders altering spontaneous ventilatory patterns, or evidence of pulmonary or systemic infection were excluded from the study.

\section{Study Methods}

Airflow (V(dot)) was measured by a Validyne $+/-2 \mathrm{cmH}_{2} 0$ transducer (Northridge, California, USA) and a low deadspace pneumotachograph (Hans Rudolf 8300 series, Kansas City, Missouri, USA). This was attached directly to an endotracheal tube or to a small face mask (size 0 Rendell-Baker Soucek Mask, London, England with deadspace $2.5 \mathrm{~mL}$ ) for the non-intubated subjects. With the face mask, a ring of sealant (Therapeutic Putty, Westbury, UK) was used to achieve an airtight seal after the method of Stocks et al. (18). Esophageal pressure (Pes) was measured by a fluid-filled catheter system, introduced either orally or nasally, and accuracy confirmed by an occlusion test according to the technique described by Asher et al. (19). Pressure at the airway opening (Pao) was determined by a Validyne $+/-50 \mathrm{cmH}_{2} 0$ transducer (Northridge, California, USA). Finally, hemoglobin oxygen saturation $\left(\mathrm{SaO}_{2}\right)$ was monitored continuously and maintained at greater than $90 \%$ by varying $\mathrm{FiO}_{2}$.

Measurements were recorded immediately before and 30 minutes after the commencement of nebulized salbutamol. All patients received $1 \mathrm{mg}$ salbutamol dispersed in $2.5 \mathrm{cc}$ of normal saline nebulized for 15 minutes in a Hudson 1820 nebulizer (Hudson Inc., Temecula, California, USA) driven at a flow rate of 6 $\mathrm{L} / \mathrm{min}$. Infants were studied supine after feeding, either in a sleeping or quiet awake state with no obvious body movements. If a quiet state was not obtained, sedation with chloral hydrate $(75 \mathrm{mg} / \mathrm{kg})$, which has been shown to exert minimal interference on pulmonary mechanics and respiratory function (20), was used.

\section{Statistical Analysis}

Data was collected using a software program (DATALAB, PBO Development Inc., Montreal, Quebec, Canada) and analyzed using a commercially available statistical package (MINITAB Inc., version 10, State College, Pennsylvania, USA). For each patient, a minimum of 15 breaths were analyzed both before and after salbutamol treatment. From this breath-by-breath analysis, respiratory frequency $(\mathrm{f})$, tidal volume $\left(\mathrm{V}_{\mathrm{T}}\right)$, and minute ventilation $\left(\mathrm{V}(\mathrm{dot})_{\mathrm{E}}\right)$ were calculated. Values for dynamic lung compliance $\left(\mathrm{C}_{\mathrm{Ldyn}}\right)$ and lung resistance $\left(\mathrm{R}_{\mathrm{L}}\right)$ were calculated according to the classical Mead-Whittenberger analysis (21). Finally, impedance $\left(\mathrm{Z}_{\mathrm{L}}\right)$ was calculated according to the method of Coates et al. (22), while Work of Breathing (WOB) was calculated from the method of Otis (23).

Data for each patient and treatment condition were expressed as mean values $+/$ - standard deviation. A paired t-test was used for statistical comparison between pre and post treatments for salbutamol. A $p$ value of less than 0.05 was considered to be statistically significant.

\section{RESULTS}

Patient characteristics prior to initiation of the study are summarized in Table 1. In total, nineteen premature infants were enrolled and all completed the study. There were eleven patients analyzed with an endotracheal tube (ETT) in situ while spontaneously breathing on continuous positive airway pressure (CPAP). A further eight subjects underwent mask studies. These results are summarized in Table 2. Two children required sedation and completed the study uneventfully.

Table 3 demonstrates the effects of salbutamol upon ventilation and respiratory mechanics of the study group. After treatment with salbutamol, overall resistance was significantly reduced $(32.1 \% ; p=0.008)$ with a tendency for impedance reduction $(p=0.078)$. Although the majority of patients had improved lung 
resistance, one infant had a paradoxical response and two infants showed no significant change. The remaining lung mechanic parameters and WOB did not show any significant trends.

\section{DISCUSSION:}

Bronchopulmonary dysplasia is the most common respiratory disease resulting from prematurity with an incidence of approximately $20 \%$ (6). The use of bronchodilators in premature infants with BPD has been controversial due to the belief that the minimal amount of smooth muscles found in their airways is insufficient to benefit from bronchodilators. However, subsequent lung histopathology studies have shown pulmonary edema and inflammation accompanied by marked presence of hypertrophied peribronchial smooth muscle cells. The increased airflow resistance in infants with BPD may be explained by the contraction of these muscle cells and, in part, by the peribronchial edema with impaired clearance of secretions (24). Although the action of salbutamol on smooth muscle is well-established, there is evidence that bronchodilators attenuate pulmonary edema and enhance the mucociliary transport of secretions $(25,26)$. This suggests that, irrespective of the final mechanism of action, the airway obstruction characteristic of BPD is potentially reversible with the use of salbutamol, a $\beta_{2}$ sympathomimetic amine.

This study demonstrates that the administration of salbutamol in very premature infants ( $<32$ weeks) with BPD results in a significant decrease in resistance $(p=0.008)$ and a tendency for impedance reduction $(p=$ 0.078 ). The majority of patients studied had improved lung resistance with a mean decrease in $\mathrm{R}_{\mathrm{L}}$ of $32.1 \%$. The magnitude of change in resistance and impedance are comparable with those seen in older BPD infants and in adults, reflecting other indicators of bronchodilation, such as changes in $\mathrm{FEV}_{1}$ and maximal midexpiratory flow rate (MMEFR). Since pre and post measurements were taken 30 minutes apart, the reduction in resistance is directly attributable to salbutamol, and not to possible confounding factors such as growth of the infant.

Impedance $\left(\mathrm{Z}_{\mathrm{L}}\right)$ represents the combined flow resistance and tissue elastic load faced by the respiratory muscles. As such, it forms a convenient parameter that reflects respiratory rate, compliance of the lung and airflow resistance (22). As either resistance increases or compliance decreases, the impedance will be augmented. Thus, this study showed a significant decrease in resistance, allowing for a trend in impedance reduction.

One infant experienced a paradoxical deterioration (which also has been noted in other studies) while two infants showed no change. These patients did not differ significantly from the rest of the study group in terms of baseline lung function nor demographics. In the two infants who did not show a change in $\mathrm{R}_{\mathrm{L}}$, underlying differences in the etiology of airway obstruction may account for the different response found in these infants (15). In the infant with a paradoxical increase in $\mathrm{R}_{\mathrm{L}}$, an initial bronchoconstrictive response to nebulized salbutamol may be related to the water used as a diluent (27). However, it is possible that this bronchoconstrictive effect may subside 30 minutes post-treatment, allowing for a subsequent positive response to salbutamol not detected by the present protocol.

In premature infants, the elevated resistance may lead to airway damage with subsequent air trapping or mal distribution of ventilation, necessitating prolonged mechanical ventilation and supplemental oxygen therapy (28). The resulting barotrauma and oxygen toxicity will increase the duration and exacerbate the severity of $\mathrm{BPD}$, thus contributing to the development of chronic lung disease (29). Early intervention to minimize airway obstruction may lead to rapid weaning from ventilatory assistance, ultimately limiting the magnitude of lung damage, and thereby interrupting the cycle. Therefore, the role of salbutamol in decreasing lung resistance would appear to be integral for the management of BPD in very premature infants $(<32$ weeks).

To our knowledge, this is the first documented study addressing the effect of $\beta_{2}$ agonist administration on 
pulmonary function in premature infants of less than 32 weeks with BPD. Given the prevalence of this disease, its high mortality and morbidity, and its potential long-term complications, further studies in this age group are clearly warranted to support these findings.

\section{ACKNOWLEDGMENTS}

The authors are indebted to Julia Mesiano and Lyne Brousseau, the respiratory therapists at the Montreal Children's Hospital, for their assistance in carrying out this study, and to Dr. Usher and the rest of the NICU staff at the Royal Victoria Hospital. This research was funded by the Medical Research Council, Pharmaceutical Manufacturers Association of Canada, Health Research Foundation and Glaxo Pharmaceutical Company.

\section{REFERENCES}

1. Northway, WH Jr., Rosan RC, Porter DY. Pulmonary disease following respiratory therapy of hyaline disease: bronchopulmonary dysplasia. New England Journal of Medicine 276(7): 357-368; 1967.

2. Farrell PM, Palta M. Bronchopulmonary Dysplasia: Clinical Presentation and Pathogenesis. In: Report of the Ninetieth Ross Conference: Bronchopulmonary Dysplasia and Related Chronic Respiratory Disorders. Ohio: Ross Laboratories; 1986: 1-6.

3. Fanburg BL, Deneke SM, Lee S, et al. Bronchopulmonary Dysplasia: Mediators of Lung Injury in Oxygen Toxicity. In: Report of the Ninetieth Ross Conference: Bronchopulmonary Dysplasia and Related Chronic Respiratory Disorders. Ohio: Ross Laboratories; 1986: 16-23.

4. Groneck P, Gotze-Speer B, Oppermann M, et al. Association of Pulmonary Inflammation and Increased Microvascular Permeability During the Development of Bronchopulmonary Dysplasia: A Sequential Analysis of Inflammatory Mediators in Respiratory Fluids of High-Risk Preterm Neonates. Pediatrics 93(5): 712-718; 1994.

5. Wood BP. The Newborn Chest. In: The Radiologic Clinics of North America - The Pediatric Chest. Philadelphia: W.B. Saunders Co.; 1993: 667 - 676.

6. Bohin S, Field DJ. The epidemiology of neonatal respiratory disease. Early Human Development. 37(2): 73-90; 1994.

7. Abman SH, Groothius JR. Pathophysiology and treatment of bronchopulmonary dysplasia. Pediatric Clinics of North America 41(2): 277-315; 1994.

8. Vohr BR, Bell EF, Oh W. Infants with bronchopulmonary dysplasia: growth pattern and neurologic and developmental outcome. American Journal of Diseases of Children 136(5): 443-447; 1982.

9. Northway WH, Moss RB, Carlisle KB, et al. Late pulmonary sequelae of bronchopulmonary dysplasia. New England Journal of Medicine 323(26): 1793-9; 1990.

10. Cloutier MM. Nebulized Steroid Therapy in Bronchopulmonary Dysplasia. Pediatric Pulmonology 15(2): 111-116; 1993.

11. Blanchard PW, Brown TM, Coates AL. Pharmacotherapy in bronchopulmonary dysplasia. Clinics in Perinatology 14(4): 881-910; 1987.

12. Kao LC, Warburton D, Sargent CW, et al. Furosemide acutely decreases airways resistance in chronic 
bronchopulmonary dysplasia. Journal of Pediatrics 103(4): 624-629; 1983.

13. Alpert BE, Allen JL, Schidlow DV. Bronchopulmonary Dysplasia. In: Hilman BC, ed. Pediatric

Respiratory Disease - Diagnosis and Treatment. Philadelphia: W.B. Suanders Co.; 1993: 440-457.

14. Gomez-Del Rio M, Gerhardt T, Herhe Disease, et al. Effect of a Beta-agonist Nebulization on Lung Function in Neonates with Increased Pulmonary Resistance. Pediatric Pulmonology 2(5); 287-291: 1986.

15. Yuksel B, Greenough A. Variable response to bronchodilator therapy in young children born prematurely. Respiratory Medicine 87(5) :359-364; 1993.

16. Wilkie RA, Bryan MH. Effect of bronchodilators on airway resistance in ventilator-dependant neonates with chronic lung disease. Journal of Pediatrics 111(2): 278-82; 1987.

17. Hyde I, English RE, Williams JD. The changing pattern of chronic lung disease of prematurity. Archives of Disease in Childhood 64(4): 448-451; 1989.

18. Stocks J, Beardsmore C, Helm P. Standardization of Lung Function tests in Paediatrics Infant Lung Function: Measurement conditions and equipment. The European Respiratory Journal-Supplement 4: 123S129S; 1989.

19. Asher MI, Coates AL, Collinge JM. Measurement of pleural pressure in neonates. Journal of Applied Physiology: Respiratory Environmental and Exercise Physiology 52(2): 491-494; 1982.

20. Anonymous. American Academy of Pediatrics Committee on Drugs, American Academy of Pediatrics Committee on Environmental Health. Use of chloral hydrate for sedation in children. Pediatrics 92(3): 471$472 ; 1993$.

21. Grimby G, Goldman M, Mead J. Respiratory muscle action inferred from rib cage and abdominal V-P partitioning. Journal of Applied Physiology 41(5): 739-751; 1976.

22. Coates AL, Vallinis P, Mullahoo K et al. Pulmonary Impedance as an Index of Severity and Mechanism of Neonatal Lung Disease. Pediatric Pulmonology 17(1): 41-49; 1994.

23. Otis AB, Fenn WO, Rahn H. The Mechanics of Breathing in Man. Journal of Applied Physiology 2(3): 592-607; 1950.

24. Zimmerman JJ. Bronchoalveolar imflammatory pathophysiology in bronchopulmonary dysplasia. Clinics in Perinatology 22(2): 429-456; 1995.

25. Rotschild A, Solimano A, Puterman M, et al. Increased compliance in response to salbutamol in premature infants with developing bronchopulmonary dysplasia. Journal of Pediatrics 115(6): 984-991; 1989.

26. Kirpalani H, Koren G, Schmidt B, et al. Respiratory response and pharmacokinetics of intravenous salbutamol in infants with bronchopulmonary dysplasia. Critical Care Medicine 18(12): 1374-1377; 1990.

27. O'Callaghan C, Milner AD, Swarbrick A. Paradoxical deterioration in lung function after nebulized salbutamol in wheezing infants. Lancet 2(8521-8522): 1424-1425; 1986.

28. Sosulski R, Abbassi S, Bhutani V, et al. Physiologic Effects of Terbutaline on Pulmonary Function of Infants with Bronchopulmonary Dysplasia. Pediatric Pulmonology 2(5): 269-273; 1986. 
29. Gorenflo M, Vogel M, Herbst L, et al. Influence of Clinical and Ventilatory Parameters on Morphology of Bronchopulmonary Dysplasia. Pediatric Pulmonology 19(4): 214-220; 1995.

\section{BIOGRAPHY}

Ha-Nam P. Nguyen received her CEGEP diploma in Health Sciences from Champlain Regional College (St. Lambert, Quebec, Canada) in 1994. She is currently a second year medical student at McGill University (Montreal, Quebec, Canada). Her research on bronchopulmonary dysplasia was conducted during her first year of medical school. Portions of the study were presented to the Association Pulmonaire du Quebec at its annual meeting in May 1996 in Montreal.

Copyright (C) 1997 by MJM 